IIIIIIIIIIIIIIIIIIIIIIIIIIIIIIIIIIII

Original Article

IIIIIIIIIIIIIIIIIIIIIIIIIIIIIIIIII

\title{
Biological properties of flutianil as a novel fungicide against powdery mildew
}

\author{
Sachi Kimura, ${ }^{1, *}$ Tomozo Komura, ${ }^{1}$ Naoto Yamaoka ${ }^{2}$ and Hisashi OKa ${ }^{3}$ \\ ${ }^{1}$ OAT Agrio, Regulatory Group, Research and Development Division, Naruto, Tokushima 772-0021, Japan \\ ${ }^{2}$ Faculty of Agriculture, Ehime University, 3-5-6 Tarumi, Matsuyama, Ehime 779-8566, Japan \\ ${ }^{3}$ OAT Agrio, Research and Development Division, Naruto, Tokushima 772-0021, Japan
}

(Received November 21, 2019; Accepted July 4, 2020)

\begin{abstract}
Flutianil, chemically characterized as a cyano-methylene thiazolidine, showed antifungal activity against powdery mildew on various crops but not any other plant pathogens tested. Flutianil showed high residual and translaminar activities and rainfastness against Podosphaera xanthii. It also exhibited curative activity against $P$. xanthii on cucumber at an extremely low concentration of $10 \mathrm{mg} / \mathrm{L}$. There was no cross-resistance between flutianil and other existing fungicides. Morphological studies revealed that flutianil did not inhibit the early infection behavior of Blumeria graminis f. sp. hordei i.e., conidium bursting, primary and appressorial germinations, appressorium development and hook formations, but it did inhibit haustorium formation and further fungal development. Nutrient absorption by haustoria and subsequent secondary hyphal elongation was inhibited by flutianil but not by the fungicide that showed a similar inhibitory pattern up to the haustorium formation stage of the infection process. These findings suggest that flutianil might have a novel mode of action.
\end{abstract}

Keywords: flutianil, fungicide, biological property, powdery mildew.

Electronic supplementary materials: The online version of this article contains supplementary material (Supplemental Table S1), which is available at https://www.jstage.jst.go.jp/browse/jpestics/

\section{Introduction}

Powdery mildew is a widespread plant disease caused by a variety of fungal species of Erysiphales. ${ }^{1)}$ Powdery mildew pathogens are known as obligate biotrophs that depend on living plant cells for their survival and reproduction. ${ }^{2}$ It is one of the most destructive fungal diseases in many crops and often causes major economic losses in agricultural production. ${ }^{3)}$ For the control of powdery mildew, various classes of chemical fungicides-such as benzimidazoles, morpholines, 2-aminopyrimidines, triazoles (sterol demethylation inhibitors: DMIs), strobilurins (QoI), azanaphthalenes, and benzophenones-have been used. The fungicides belonging to each of these classes have a specific action target in the pathogen and high efficacy with lowconcentration treatment. ${ }^{3-8)}$ Frequent use of these selective fungicides has resulted in the emergence of resistant populations of

\footnotetext{
* To whom correspondence should be addressed.

E-maila: sachi-kimura@oat-agrio.co.jp

Published online September 1, 2020
}

(c) BY-NC-ND (c) Pesticide Science Society of Japan 2020. This is an open access article distributed under the Creative Commons AttributionNonCommercial-NoDerivatives 4.0 International (CC BY-NC-ND 4.0) License (https://creativecommons.org/licenses/by-nc-nd/4.0/) the target pathogen. ${ }^{9)}$ In particular, powdery mildew pathogens were shown to have a high potential for developing resistance to single site-targeted fungicides, the overexpression of the sitetargeted gene, and/or efflux transportation that pumps out endogenous compounds from the cells. Therefore, demand for a fungicide with a novel mode of action against powdery mildew has been increasing.

This paper deals with the biological properties of a novel fungicide, flutianil, (Gatten ${ }^{\circledR},(2 Z)-\{[2$-fluoro-5-(trifluoromethyl)phenyl] sulfanyl\}[3-(2-methoxyphenyl)-1,3-thiazolidin-2ylidene] acetonitrile) (chemical structure shown in Fig. 1), which was discovered through extensive studies on the synthesis and biological screening of the cyano-methylene thiazolidine chemical class. ${ }^{10)}$ Flutianil has proved to be a unique fungicide, since its antifungal spectrum covers only powdery mildew species, in-

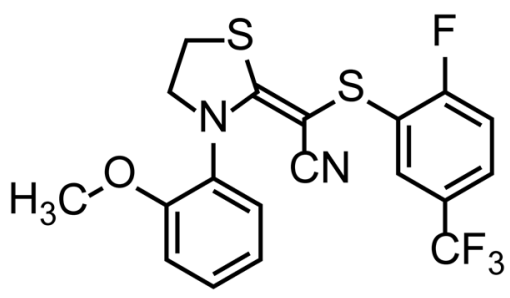

Fig. 1. Chemical structure of flutianil. 
cluding Podosphaera xanthii, Sphaerotheca fuliginea, Erysiphe necator, Sphaerotheca aphanis var. aphanis, Blumeria graminis f. sp. tritici (Bgt), and Blumeria graminis f. sp. hordei (Bgh). We will report on flutianil's antifungal spectrum, residual and translaminar activities, rainfastness, cross-resistance with other existing fungicides, and curative activity, as well as its inhibitory effect on haustorium formation and sporulation.

Since flutianil is currently classified as a part of Fungicide Resistance Action Committee (FRAC) Group U 13, ${ }^{11)}$ meaning it has an unknown mode of action, a description of the findings that led to the elucidation of the mode of action of flutianil is also made.

\section{Materials and Methods}

\section{Chemicals}

Synthesized flutianil and cyflufenamid analytical standards were used for all laboratory studies, including in vitro fungal spectrum and microscopy analyses. Triflumizole, azoxystrobin, tolfenpyrad, quinoxyfen, benomyl, and chinomethionat were purchased from FUJIFILM Wako Pure Chemical Corporation (Osaka, Japan). Metrafenone was purchased from SigmaAldrich (Tokyo, Japan). Stock fungicide solutions were prepared by dissolving each compound in acetone and diluting it with distilled water to make a test solution with $<1 \%$ acetone (v/v).

For pot tests and the cross-resistance study, the following formulated ingredients were used: $50 \mathrm{~g} / \mathrm{kg}$ flutianil EC, $200 \mathrm{~g} / \mathrm{kg}$ azoxystrobin SC, $300 \mathrm{~g} / \mathrm{kg}$ triflumizole WP, a mixture of $34 \mathrm{~g} /$ $\mathrm{kg}$ cyflufenamid and $150 \mathrm{~g} / \mathrm{kg}$ triflumizole WDG, $200 \mathrm{~g} / \mathrm{kg}$ penthiopyrad SC, $250 \mathrm{~g} / \mathrm{kg}$ chinomethionat WP, $300 \mathrm{~g} / \mathrm{kg}$ iminoctadine albesilate SC, $250 \mathrm{~g} / \mathrm{kg}$ quinoxyfen SC, and $250 \mathrm{~g} / \mathrm{kg}$ tebuconazole EW.

\section{Biological properties}

\subsection{Preparation of test plants}

Wheat seeds (Triticum aestivum cv. Chikugoizumi) were sown in plastic trays with 128 cells $(59.5 \times 30 \times 50 \mathrm{~mm})$ filled with culture soil (Aisai 1-go, Katakura \& Co-Op Agri, Tokyo, Japan). The plastic trays were placed in a growth chamber at $23^{\circ} \mathrm{C}$ with $60 \%$ relative humidity $(\mathrm{RH})$ under a $16 \mathrm{hr}$ photoperiod for 7 days. Seeds of cucumber (Cucumis sativus cv. Suzunari-suyo), eggplant (Solanum melongena cv. Senryo), pea (Pisum sativum cv. Narikoma-sanjyunichi), and tomato (Solanum lycopersicum cv. Momotaro Eight) were sown in $7.5 \mathrm{~cm}$ diameter polyethylene pots filled with the same culture soil used for wheat sowing and placed in a greenhouse for 21 days. Grapes (Vitis vinifera $\mathrm{cv}$. Pione) were planted in $9 \mathrm{~cm}$ diameter polyethylene pots filled with the same culture soil used for sowing wheat and placed in a greenhouse. Rice seeds (Oryza sativa subsp. japonica cv. Koshihikari) were sown in plastic trays with 128 cells $(59.5 \times 30 \times 50 \mathrm{~mm})$ filled with culture soil (Ube-ryujyobaido, Katakura \& Co-Op Agri, Tokyo, Japan) and placed in a greenhouse. Rice plants grown to approximately the 1.2 leaf stage (about two weeks after seeding) were used for experiments. Strawberry plants (Fragaria $\times$ ananassa $\mathrm{cv}$. Akihime) were plant- ed in $7.5 \mathrm{~cm}$ diameter polypropylene pots filled with the same culture soil used for sowing wheat and grown in a greenhouse.

\subsection{Fungicide treatment and pathogen inoculation}

A conidial suspension $\left(10^{5}\right.$ conidia/mL $)$ of $P$. xanthii or the conidial dust of $S$. fuliginea, which had been maintained on cucumbers or eggplants in a laboratory, respectively, was inoculated onto the leaves $3 \mathrm{hr}$ after treatment with $10 \mathrm{mg} / \mathrm{L}$ of flutianil (unless otherwise noted, the treatment concentration of flutianil was $10 \mathrm{mg} / \mathrm{L})$. For E. necator, a conidial suspension $\left(10^{5}\right.$ conid$\mathrm{ial} / \mathrm{mL}$ ) was inoculated onto grape leaves $3 \mathrm{hr}$ after treatment with flutianil. In cases of Bgt and Bgh, wheat or barley was treated with flutianil and inoculated with powdery mildew by exposing each treated plant to a conidial dust of Bgt and Bgh strains that had been maintained on each plant in a laboratory. In the case of $B$. cinerea, flutianil treatment and the inoculation procedure are as follows: flutianil-treated cucumber cotyledons were excised and placed in a wet paper-lined plastic case to maintain the humidity in the case. A $50 \mu \mathrm{L}$ spore suspension of $B$. cinerea $\left(1 \times 10^{5}\right.$ spores $\left./ \mathrm{mL}\right)$ in YG medium $(10 \mathrm{~g}$ yeast extracts and $20 \mathrm{~g}$ glucose per liter) was placed onto the cucumber leaves and covered with a paper disc (Toyo Roshi Kaisha, Tokyo, Japan). A $50 \mu \mathrm{L}$ YG medium was then added onto the paper disc. For $P$. fulva and $M$. nattrassii, a conidial suspension $\left(10^{6}\right.$ conidia $\left./ \mathrm{mL}\right)$ prepared from a potato dextrose agar (PDA) culture was inoculated onto tomato or eggplant leaves $3 \mathrm{hr}$ after treatment with flutianil. The inoculated plants were then kept in a dew chamber $(100 \% \mathrm{RH})$ at $25^{\circ} \mathrm{C}$ for $24 \mathrm{hr}$ and then kept in a growth chamber. In the case of $G$. cingulata, flutianil treatment and the inoculation procedure are as follows: $G$. cingulata was grown on a PDA medium plate for 5 days in darkness at $25^{\circ} \mathrm{C}$. A potato sucrose (PS) liquid medium containing $20 \%$ (v/v) potato broth and $20 \mathrm{~g} / \mathrm{L} \mathrm{su}-$ crose was inoculated with the tip of a mycelium disc and then shaken at $130 \mathrm{rpm}$ for 5 days at $25^{\circ} \mathrm{C}$ to produce conidia. The conidial suspension $\left(1.0 \times 10^{6}\right.$ conidia $\left./ \mathrm{mL}\right)$ thus obtained was inoculated to flutianil-treated strawberry plants. The inoculated plants were then kept in a dew chamber $(100 \% \mathrm{RH})$ at $25^{\circ} \mathrm{C}$ in the dark for $24 \mathrm{hr}$ and then in a growth chamber. For P. infestans the conidial suspension $\left(10^{5}\right.$ conidia $\left./ \mathrm{mL}\right)$ which was grown on detached tomato leaves at $15^{\circ} \mathrm{C}$ for 7 days, was inoculated onto the flutianil-treated plants. The inoculated plants were kept in a dew chamber $(100 \% \mathrm{RH})$ at $20^{\circ} \mathrm{C}$ for $24 \mathrm{hr}$ and then in a growth chamber. For P. oryzae inoculation, $P$. oryzae was isolated from the field and grown in a laboratory on a culture medium containing $5 \%(\mathrm{w} / \mathrm{v})$ oatmeal and $2 \%(\mathrm{w} / \mathrm{v})$ sucrose for 14 days at $25^{\circ} \mathrm{C}$ in darkness. Spore formation was induced by placing the cultures under a $20 \mathrm{~W}$ blacklight blue (BLB) fluorescent lamp for 3 days at $25^{\circ} \mathrm{C}$. The spore suspension $\left(10^{5}\right.$ conidia $\left./ \mathrm{mL}\right)$ thus obtained was sprayed onto rice leaves $3 \mathrm{hr}$ after treatment with flutianil. The inoculated plants were kept in a dew chamber $(100 \% \mathrm{RH})$ at $25^{\circ} \mathrm{C}$ in darkness for $24 \mathrm{hr}$ and then in a growth chamber.

\subsection{Evaluation of activity}

The lesions on the inoculated leaves were observed, and the grading ranged from 0 to 4 , where 0 indicated no lesions, 1 indicated lesions occupying less than 5\% of the leaf area, 2 indicated 
lesions occupying 5-25\% of the leaf area, 3 indicated lesions occupying $25-50 \%$ of the leaf area, and 4 indicated lesions occupying more than $50 \%$ of the leaf area. A control value $(\mathrm{CV})$ was calculated using the following formula:

$$
\mathrm{CV}=(1-\mathrm{T} / \mathrm{C}) \times 100
$$

Here, $\mathrm{T}$ represents the index of the leaf area covered with lesions on the treated plants, and $\mathrm{C}$ represents the index of the leaf area covered with lesions on the untreated plants.

\section{Residual activity and rainfastness}

To examine the residual activity of flutianil, flutianil-sprayed cucumber seedlings were kept in a greenhouse for 14 days, followed by inoculation with $P$. xanthii, and the antifungal activity was measured. To examine the rainfastness, flutianilsprayed cucumber plants were kept for $24 \mathrm{hr}$ in a greenhouse and then exposed to artificial rain $(40 \mathrm{~mm} / \mathrm{hr}$; raindrop particle size $=1.75 \mathrm{~mm}$ ) for $2 \mathrm{hr}$ using an artificial rain generator (DIK6000-S, Daiki Rika Kogyo, Saitama, Japan). The plants were then inoculated with a conidial suspension of $P$. xanthii and subjected to activity measurement.

\section{Translaminar and systemic activities of flutianil in cucumber plants}

Translaminar and systemic activities of flutianil were investigated in a greenhouse. To examine the translaminar activity, a sufficient amount of flutianil was applied with a brush either to the adaxial (a) or the abaxial (b) surfaces of cucumber leaves; both sides of the leaves were inoculated with $P$. xanthii after $24 \mathrm{hr}$ and the control effect was measured. To examine systemic activity, a sufficient amount of flutianil solution was applied with a brush to the base or apex of cucumber leaves and with a pipette to the soil around the cucumber plants. The plants were inoculated with $P$. xanthii $24 \mathrm{hr}$ after flutianil treatment, and the control effect was measured.

\section{Cross-resistance and sensitivity study of flutianil}

5.1. Cross-resistance study with $\mathrm{P}$. xanthii and $\mathrm{S}$. aphanis var. aphanis

The sensitivities of flutianil to the powdery mildew isolates $(P$. xanthii) collected from cucumbers in 12 locations in Japan and to the powdery mildew isolates (S. aphanis var. aphanis) collected from strawberries in 8 locations in Japan were compared with those to other fungicides of various chemical classes, i.e., azoxystrobin (QoI), triflumizole (DMI), a mixture of cyflufenamid and triflumizole, penthiopyrad, chinomethionat, and iminoctadine albesilate. The isolates mentioned above were collected from 2007 to 2013 in cucumber or strawberry cultivation houses. The efficacies of flutianil and other fungicides on the $P$. xanthii isolates were determined by pot test. The efficacies of flutianil and other fungicides on S. aphanis var. aphanis were determined by using leaf discs of strawberry plants (cv. Nyohou). Young strawberry leaves were used for the experiment because of their high sensitivity to pathogens. The leaves were then cut into discs ( $10 \mathrm{~mm}$ in diameter) which were placed into Petri dishes with their upper surfaces down. The concentration of flutianil used for treatment was 0.03 to $10 \mathrm{mg} / \mathrm{L}$. The concentration of the other fungicides was set as stated on the product labels. The test solutions were then sprayed onto the strawberry leaf discs. After air-drying, the leaf discs were inoculated, and the discs were kept in a greenhouse for 7 days. Then, each disc was visually graded on the degree of fungus attack by observing the entire disc surface using a stereoscopic microscope (Nikon, Tokyo, Japan). The grading ranged from 0 to 4 , where 0 indicated no lesions, 1 indicated lesions occupying less than $5 \%$ of the disc area, 2 indicated lesions occupying 5-25\% of the disc area, 3 indicated lesions occupying $25-50 \%$ of the disc area, and 4 indicated lesions occupying more than $50 \%$ of the disc area. Fungicide efficacy was calculated using the method described in Section 2.3.

5.2. Cross-resistance study with E. necator isolates in Europe Ten E. necator isolates were selected from a 30 E. necator-isolate library from Europe and maintained in our laboratory. These isolates have different sensitivities to sterol demethylation inhibitor (DMI) fungicides and/or quinoxyfen. Cross-resistance tests were carried out using leaf discs of vine plants (Vitis vinifera $\mathrm{cv}$. Cinsaut). Young glossy leaves were collected because of their high sensitivity to the pathogen. Vine leaves were sterilized for $30 \mathrm{sec}$ in a $50 \mathrm{~g} / \mathrm{L}$ sodium hypochlorite solution and then rinsed twice with sterile water before being dried by sandwiching them between two pieces of sterile filter paper. The leaves were then cut into discs (18 $\mathrm{mm}$ in diameter) and placed in petri dishes followed by treatment with fungicides. The treatment concentrations were $0.003,0.01,0.33,0.1,0.3,1$, and $3 \mathrm{mg} / \mathrm{L}$ for flutianil; $0.01,0.1,0.3,1,3,10,30$, and $100 \mathrm{mg} / \mathrm{L}$ for tebuconazole; and $0.1,0.3,1,3,10,30$, and $100 \mathrm{mg} / \mathrm{L}$ for quinoxyfen. The fungicides were applied directly to the upper surfaces of the leaf discs.

\section{Curative treatment with flutianil}

Flutianil $(10 \mathrm{mg} / \mathrm{L})$ was applied to the cucumber leaves, which were inoculated with a conidial suspension 1 day after the inoculation (pre-symptoms), and then 5, 7, 9, 12, and 14 days after the inoculation (post-symptoms). The curative activity of flutianil against $P$. xanthii was evaluated by visual assessment each day up to 14 days after inoculation. Mycelium formation and sporulation were observed 7 days after the application. Observations were made using a light microscope (Keyence VHX200, Osaka, Japan) on four sites of the first cucumber leaves, and the experiments were repeated three times. A secondary infection study was conducted using the cucumber plants from the curative activity study as an infection source. A non-infected cucumber cotyledon was inoculated by rubbing it against the infected plant. Seven days after inoculation, the presence or absence of powdery mildew in cucumber cotyledons was observed.

\section{Light microscopic observation of infection behavior}

Barley powdery mildew ( $B g h$ ) was used as the observation target of the infection behavior. Barley seedlings (Hordeum vulgare cv. 
Kobinkatagi) were grown in culture soil in a growth chamber under fluorescent light (approx. $11.8 \mathrm{~W} / \mathrm{m}$ ) with a $12 \mathrm{hr}$ photoperiod at $20^{\circ} \mathrm{C}$ and $70 \% \mathrm{RH}$. Coleoptiles were excised from barley seedlings 7 days after sowing and single-cell epidermal layers of partially dissected coleoptiles were prepared as previously described. ${ }^{12)}$ The coleoptiles floated on $1 \mathrm{mM}$ calcium chloride $\left(\mathrm{CaCl}_{2}\right)$ in a Petri dish containing $10 \mathrm{mg} / \mathrm{L}$ of flutianil and other existing fungicides were inoculated with freshly harvested $B g h$ conidia using a brush and incubated at $20^{\circ} \mathrm{C}$ for $24 \mathrm{hr}$. Each coleoptile was placed in $1 \mathrm{mM} \mathrm{CaCl}$ on a glass slide. Infection behaviors-conidium bursting, primary germ tube (PGT) germination, appressorial germ tube (AGT) germination, appressorial (APP) formation, APP hook formation, and haustorium formation of Bgh conidia on coleoptiles-were observed under a light microscope (Nikon, Osaka, Japan) at $200 \times$ magnification.

In order to measure the effect of the addition of nutrients to haustoria for the elongation of secondary hyphae, the coleoptiles in the Petri dish were incubated with the test compounds at $20^{\circ} \mathrm{C}$ for $24 \mathrm{hr}$, followed by addition of $0.1 \mathrm{M}$ glucose as a nutrient. The coleoptiles were placed on a slide glass in preparation for microscopic observation. Then, $24 \mathrm{hr}$ later, the elongation of secondary hyphae was measured using eyepiece scales.

\section{Scanning electron microscopy}

Cucumber plants at the 1.2-leaf stage were inoculated with $P$. xanthii and incubated for 7 days in a greenhouse. Flutianil $(10 \mathrm{mg} / \mathrm{L})$ was applied to the inoculated cucumber leaves and then maintained for 7 days in a greenhouse. The test plants were subjected to observation with a low-temperature cryofixation scanning electron microscope S-3400N (Cryo-SEM, Hitachi High-Tech, Tokyo, Japan). Observations were made for $5 \times 5 \mathrm{~mm}$ pieces of cut leaf tissue placed on a specimen cooling stage and then transferred to the preparation chamber. Then, Cyro-SEM observations were performed $-120^{\circ} \mathrm{C}$ at low voltage $(5 \mathrm{kV})$ - using a secondary electron detector.

\section{Results}

\section{Antifungal spectrum of flutianil}

The antifungal activity of flutianil against different fungal species was investigated. No antifungal activity was observed in vitro against 24 investigated species of various pathogens (Table S1). Pot tests for the effects of flutianil on various pathogens indicated that flutianil did not show any efficacy-even at a high concentration of $500 \mathrm{mg} / \mathrm{L}$-against B. cinerea, $P$. fulva, G. cingulata, M. nattrassii, P. infestans, and P. oryzae (Table 1). On the contrary, flutianil at $10 \mathrm{mg} / \mathrm{L}$ exhibited high activity $(100 \%$ control) against powdery mildew on cucumber, eggplant, grape, and wheat. These results indicate that flutianil is effective only against powdery mildew on certain crops.

\section{Residual activity and rainfastness of flutianil}

The residual activity of flutianil was measured using flutianiltreated cucumber kept in a greenhouse for 14 days before inoculation. Flutianil at $10 \mathrm{mg} / \mathrm{L}$ exhibited $100 \%$ control against $P$. xanthii and the activity was maintained for at least 14 days. The rainfastness of flutianil was measured by placing the flutianiltreated cucumbers under artificial rainfall for either 3 or $24 \mathrm{hr}$. Flutianil at $10 \mathrm{mg} / \mathrm{L}$ maintained a high level of activity with both 3 and $24 \mathrm{hr}$ of rainfall (control value: 100\%). These results indicate that flutianil has excellent residual activity and rainfastness.

\section{Translaminar and systemic activity of flutianil}

When flutianil was applied only on the adaxial or abaxial surfaces of cucumber leaves, it exhibited high control of pathogens existing on other leaf surfaces, control values being over $90 \%$ at $1 \mathrm{mg} / \mathrm{L}$ (Table 2). Thus, flutianil exhibits excellent translaminar activity. However, flutianil did not show any systemic activity since no control value was observed in inoculated cucumber leaves when flutianil was applied to the soil around cucumber plants. Flutianil did not show even local systemic activity, since only $40-50 \%$ control values were obtained when flutianil was

Table 1. Efficacy of flutianil against various diseases in pot test

\begin{tabular}{|c|c|c|c|c|c|c|c|c|}
\hline \multirow{2}{*}{ Disease } & \multirow{2}{*}{ Crop } & \multirow{2}{*}{ Fungal species } & \multicolumn{6}{|c|}{ Control value $e^{c)}$} \\
\hline & & & $500^{a)}$ & 200 & 10 & 1 & 0.1 & 0.01 \\
\hline Powdery mildew & Cucumber & Podosphaera xanthii & 100 & 100 & 100 & 100 & 100 & 50 \\
\hline Powdery mildew & Eggplant & Sphaerotheca fuliginea & $\mathrm{NT}^{b)}$ & NT & 100 & 100 & NT & NT \\
\hline Powdery mildew & Grape & Erysiphe necator & NT & NT & 100 & 100 & 100 & NT \\
\hline Powdery mildew & Wheat & Blumeria graminis f. sp. tritici & 100 & 100 & 100 & NT & NT & NT \\
\hline Powdery mildew & Barley & Blumeria graminis f. sp. hordei & 100 & 100 & 100 & NT & NT & NT \\
\hline Gray mold & Cucumber & Botrytis cinerea & 0 & 0 & NT & NT & NT & NT \\
\hline Leaf mold & Tomato & Passalora fulva & 0 & NT & NT & NT & NT & NT \\
\hline Anthracnose & Strawberry & Glomerella cingulata & 0 & NT & NT & NT & NT & NT \\
\hline Leaf mold & Eggplant & Mycovellosiella nattrassii & 0 & NT & NT & NT & NT & NT \\
\hline Late blight & Tomato & Phytophthora infestans & 0 & $\mathrm{NT}$ & NT & $\mathrm{NT}$ & NT & NT \\
\hline Blast & Rice & Pyricularia oryzae & 0 & 0 & NT & NT & NT & NT \\
\hline
\end{tabular}

${ }^{a)}$ Concentration of flutianil (mg/L). ${ }^{b)}$ NT: Not Tested. ${ }^{c} n=3$. 
Table 2. Translaminar and systemic activities of flutianil in cucumber plant

\begin{tabular}{|c|c|c|c|c|c|}
\hline \multirow{3}{*}{$\begin{array}{l}\text { Concentration of Flutianil } \\
\qquad(\mathrm{mg} / \mathrm{L})\end{array}$} & \multicolumn{5}{|c|}{ Control value ${ }^{f)}$} \\
\hline & \multicolumn{2}{|c|}{ Translaminar activity } & \multirow{2}{*}{$\begin{array}{c}\text { Systemic activity } \\
\text { Soil to } \\
\text { 1st stage of leaf }{ }^{c)}\end{array}$} & \multicolumn{2}{|c|}{ Local-systemic activity } \\
\hline & Adaxial to abaxial ${ }^{a}$ & Abaxial to Adaxial $\left.{ }^{b}\right)$ & & From base to apex ${ }^{d}$ & From apex to base ${ }^{e)}$ \\
\hline 10 & 100 & 100 & 0 & 50 & 40 \\
\hline 1 & 100 & 90 & 0 & 27 & 10 \\
\hline
\end{tabular}

a), b) Flutianil was applied with a brush to the adaxial-leaf surface (a) or the abaxial (b) surfaces of the cucumber leaf 24 hr before inoculating $P$. xanthii. ${ }^{c)}$ Flutianil was applied in the soil $24 \mathrm{hr}$ before inoculating $P$. xanthii. ${ }^{d)}$, e) Flutianil was applied on the base (d) or apex (e) of 1 st stage of cucumber leaf $24 \mathrm{hr}$ before inoculating P. xanthii. ${ }^{f)}$ Control value was determined by observing the area of lesion of the 1 st stage of leaves. $n=3$ plants per treatment.

applied either on the base or apex of the cucumber leaf after inoculating the entire leaf with $P$. xanthii (Table 2). These data indicate that flutianil used to treat cucumber plants moved from the leaf surface to the opposite leaf surface but was not translocated throughout the entire plant nor moved from base to apex or apex to base within the leaf.

\section{Cross-resistance study}

Cross-resistance studies between flutianil and other existing (commercially available) fungicides were conducted using the isolates collected from cucumbers, strawberries, and grapes. The existing fungicides used in the studies were azoxystrobin (QoI, FRAC code 11), triflumizole (C14 demethylation inhibitor, FRAC code 3), a mixture of cyflufenamid (unknown mode of action, FRAC code U 06) and triflumizole, penthiopyrad (succinate dehydrogenase inhibitor, FRAC code 7), chinomethionat (multi-site contact activity, FRAC code M 10), and iminoctadine albesilate (multi-site contact activity, FRAC code M 07). Table 3 shows the efficacy of flutianil and four other fungicides against
12 isolates of $P$. xanthii collected from cucumbers in various locations of Japan. Flutianil (EC) completely controlled all isolates at concentrations of 1 and $10 \mathrm{mg} / \mathrm{L}$, while, azoxystrobin, triflumizole, a mixture of cyflufenamid and triflumizole, and penthiopyrad were less effective against some $P$. xanthii isolates.

Table 4 shows the efficacy of flutianil and six other fungicides against eight isolates of $S$. aphanis var. aphanis collected from strawberries in various locations of Japan. Flutianil (EC) completely controlled all 8 isolates at concentrations of 3.3 and $10 \mathrm{mg} / \mathrm{L}$, while, azoxystrobin, chinomethionat, triflumizole, a mixture of cyflufenamid and triflumizole, iminoctadine albesilate, and penthiopyrad were less effective against some $S$. aphanis var. aphanis isolates. These findings indicate that there is no cross-resistance between flutianil and other existing fungicides for P. xanthii and S. aphanis var. aphanis.

Table 5 shows representative data for the $\mathrm{EC}_{50}$ values of flutianil and two other fungicides-quinoxyfen (signal transduction, FRAC code 13) and tebuconazole (C14 demethylation inhibitor, FRAC code 3)-against the E. necator isolate collect-

Table 3. Efficacy of flutianil against a Podosphaera xanthii pathogen collected from cucumbers in various location of Japan

\begin{tabular}{|c|c|c|c|c|c|c|c|c|c|c|c|c|c|}
\hline \multirow{3}{*}{ Compound } & \multirow{3}{*}{$\begin{array}{l}\text { Conc. } \\
(\mathrm{mg} / \mathrm{L})^{a)}\end{array}$} & \multicolumn{12}{|c|}{ Control value } \\
\hline & & $\mathrm{Lab}^{b)}$ & $\mathrm{ST}^{c}-1$ & SG-1 & IB-1 & ST-3 & $\mathrm{CB}-1$ & IB-4 & NI-1 & $\mathrm{CB}-5$ & TK-1 & KU-3 & TK-2 \\
\hline & & Jun-07 & Jul-07 & Aug-07 & Aug-07 & Jun-08 & Jul-08 & Jul-08 & Sep-08 & Oct-11 & Jun-12 & Apr-13 & Jul-13 \\
\hline \multirow[t]{6}{*}{ Flutianil 5EC } & 10 & 100 & 100 & 100 & 100 & 100 & 100 & 100 & 100 & 100 & 100 & 100 & 100 \\
\hline & 3.3 & 100 & 100 & 100 & 100 & 100 & 100 & 100 & 100 & 100 & 100 & 100 & 100 \\
\hline & 1 & 100 & 100 & 100 & 100 & 100 & 100 & 100 & 100 & 100 & 100 & 100 & 100 \\
\hline & 0.3 & 70 & 100 & 100 & 100 & 100 & 100 & 100 & 100 & 100 & 83 & 50 & 100 \\
\hline & 0.1 & 50 & 63 & 100 & 90 & 91 & 50 & 100 & 100 & 85 & 54 & 20 & 55 \\
\hline & 0.03 & 30 & 50 & 71 & 60 & 13 & 38 & 0 & 50 & 55 & 17 & 0 & 0 \\
\hline \multirow[t]{2}{*}{ Azoxystrobin 20SC } & 133 & 10 & 25 & 48 & 70 & 6 & 0 & 3 & 20 & $\mathrm{NT}^{d)}$ & 0 & 0 & 10 \\
\hline & 13.3 & 0 & 4 & 25 & 40 & 0 & 0 & 0 & 0 & NT & 0 & NT & NT \\
\hline \multirow[t]{2}{*}{ Trifumizol 30WP } & 100 & 100 & 91 & 94 & 30 & 19 & 56 & 90 & 100 & NT & NT & NT & NT \\
\hline & 10 & 10 & 29 & 0 & 20 & 0 & 0 & 15 & 45 & NT & NT & NT & NT \\
\hline \multirow{2}{*}{$\begin{array}{l}\text { Cyflufenamid }+ \\
\text { Triflumizole } 3.4+15 \text { WDG }\end{array}$} & $17+75$ & 100 & 75 & 29 & 30 & 31 & 38 & 25 & 90 & 95 & 0 & 0 & 5 \\
\hline & $1.7+7.5$ & 100 & 29 & 0 & 20 & 0 & 0 & 0 & 25 & 50 & 0 & NT & NT \\
\hline \multirow[t]{2}{*}{ Penthiopyrad 20SC } & 100 & 100 & NT & NT & NT & NT & NT & NT & NT & 98 & 42 & 10 & 25 \\
\hline & 10 & 75 & NT & NT & NT & NT & NT & NT & NT & 60 & 4 & NT & NT \\
\hline
\end{tabular}

a) Conc, concentration of test compounds. ${ }^{b}$ Lab, maintained in OAT Agrio's laboratory. ${ }^{c}$ Sampling prefecture, abbreviations: ST, Saitama; SG, Saga; IB, Ibaraki; CB, Chiba; NI, Niigata; TK, Tokushima; KU, Kumamoto. ${ }^{d)}$ NT: Not Tested. 
Table 4. Efficacy of flutianil against a Sphaerotheca aphanis var. aphanis pathogen collected from strawberries in various location of Japan

\begin{tabular}{|c|c|c|c|c|c|c|c|c|c|}
\hline \multirow{3}{*}{ Compound } & \multirow{3}{*}{$\begin{array}{l}\text { Conc. } \\
\left.(\mathrm{mg} / \mathrm{L})^{a}\right)\end{array}$} & \multicolumn{8}{|c|}{ Control value } \\
\hline & & Lab- $2^{b)}$ & $\mathrm{SM}^{c}-1$ & SG-2 & TC-7 & SZ-1 & TC-9 & TK-3 & KU-1 \\
\hline & & Nsov-11 & Feb-09 & May-10 & May-10 & May-10 & Nov-11 & Nov-11 & May-12 \\
\hline \multirow[t]{6}{*}{ Flutianil 5EC } & 10 & 100 & 100 & 100 & 100 & 100 & 100 & 100 & 100 \\
\hline & 3.3 & 100 & 100 & 100 & 100 & 100 & 100 & 100 & 100 \\
\hline & 1 & 88 & 100 & 100 & 78 & 88 & 93 & 71 & 88 \\
\hline & 0.3 & 58 & 70 & 88 & 83 & 67 & 61 & 46 & 88 \\
\hline & 0.1 & 46 & 37 & 75 & 52 & 50 & 68 & 42 & 17 \\
\hline & 0.03 & 50 & 23 & $\mathrm{NT}^{d)}$ & NT & NT & 61 & 21 & NT \\
\hline Azoxystrobin 20SC & 133 & 100 & 80 & 100 & 78 & 54 & 100 & 100 & 71 \\
\hline Chinomethionat 25WP & 83.3 & 19 & 53 & 100 & 87 & 42 & 82 & 8 & 8 \\
\hline Triflumizole 30WP & 150 & 76 & 7 & 100 & 70 & 21 & 93 & 96 & 100 \\
\hline Cyflufenamid+Triflumizole $3.4+15$ WDG & $17+75$ & 39 & 23 & 100 & 65 & 50 & 100 & 92 & 33 \\
\hline Iminoctadine albesilate 30SC & 150 & 53 & NT & 100 & 78 & 83 & 93 & 46 & 25 \\
\hline Penthiopyrad 20SC & 100 & 76 & NT & NT & NT & NT & 93 & 96 & 100 \\
\hline
\end{tabular}

${ }^{a)}$ Conc, concentration of test compounds. ${ }^{b)}$ Lab, maintained in the OAT Agrio's laboratory. ${ }^{c}$ Sampling prefecture, abbreviations: SM, Shimane; SG, Saga; TC, Tochigi; SZ, Shizuoka; TK, Tokushima; KU, Kumamoto. ${ }^{d)}$ Not tested.

ed from grapes in various areas in Europe. The $\mathrm{EC}_{50}$ values for flutianil ranged from 0.01 to $0.18 \mathrm{mg} / \mathrm{L}$, with the median value being $0.08 \mathrm{mg} / \mathrm{L}$ (some $\mathrm{EC}_{50}$ data not shown in the table were used for calculation). $\mathrm{EC}_{50}$ values for quinoxyfen ranged from 0.01 to $>100 \mathrm{mg} / \mathrm{L}$, with the median value being $>100 \mathrm{mg} / \mathrm{L}$, indicating considerable variation in the $\mathrm{EC}_{50}$ values among the isolates tested. The $\mathrm{EC}_{50}$ values for tebuconazole also varied widely, between 0.05 and $16.4 \mathrm{mg} / \mathrm{L}$, with the median value being $5.71 \mathrm{mg} / \mathrm{L}$. As shown in Fig. 2, there were no positive correlations between the $\mathrm{EC}_{50}$ values of flutianil and quinoxyfen (Fig. 2A) and/or tebuconazole (Fig. 2B). These data indicate that there was no cross-resistance between flutianil and quinoxyfen or tebuconazole for E. necator located in Europe.

5. Light microscopic observation of the effect of flutianil on Bgh conidial development

The effects of flutianil on the infection process of Bgh conid- ia were investigated using barley coleoptiles treated with 1 or $10 \mathrm{mg} / \mathrm{L}$ of flutianil and, at the same time, inoculated with $B g h$ conidia. Light microscopic observation $24 \mathrm{hr}$ after the inoculation indicated that flutianil had almost no effect on conidial germination, PGT germination, AGT germination, APP formation, and APP hook formation in the early infection process of $B g h$, but it significantly inhibited haustorium development (see Fig. 3 for infection process and morphological terminology). The rates of haustorium formation were only 3 and $9 \%$ by treatment with flutianil of 1 and $10 \mathrm{mg} / \mathrm{L}$, respectively (Fig. 4). For comparison, 4 existing fungicides-cyflufenamid, benomyl, tolfenpyrad and triflumizole-were subjected to haustorium formation studies in the same manner as flutianil. The inhibitory rates of haustorium formation by cyflufenamid, benomyl, and tolfenpyrad, were the same as that of flutianil, but the inhibitory rate by triflumizole was significantly lower, as shown in Fig. 4.

Then, the inhibitory pattern of flutianil-inhibiting only haus-

Table 5. Efficacy of flutianil against Erysiphe necator pathogen collected from grapes in various areas in Europe

\begin{tabular}{|c|c|c|c|c|c|c|c|}
\hline \multirow{2}{*}{ Strains } & \multirow{2}{*}{ Country } & \multirow{2}{*}{ Areas } & \multirow{2}{*}{ Location } & \multirow{2}{*}{$\begin{array}{c}\text { Date of } \\
\text { sampling }\end{array}$} & \multicolumn{3}{|c|}{$\mathrm{EC}_{50}$ values $(\mathrm{mg} / \mathrm{L})$} \\
\hline & & & & & flutianil & quinoxyfen & tebuconazole \\
\hline 5FBA01 & France & Languedoc & Boges & 22-May-05 & 0.02 & 0.08 & 0.05 \\
\hline 7FBR03 & France & Armagnac & Bretagne d'Armagnac & 14-Aug-07 & 0.02 & 2.90 & 3.93 \\
\hline 7PGR01 & Portugal & Oete & Gradil & 23-Jul-07 & 0.10 & 1.15 & 0.72 \\
\hline 7IMT02 & Italy & Marche & Mont-prandone & 28-Aug-07 & 0.12 & 49.49 & 14.36 \\
\hline 7FMB01 & France & Loire valley & Montreuil Bellay & 26-Sep-07 & 0.18 & 54.74 & 4.06 \\
\hline 7GAL01 & Germany & Rhein-hessen & Alzey & $16-$ Oct- 07 & 0.08 & 2.10 & 16.37 \\
\hline 5FBR01 & France & Languedoc & Brouilla & 6-Oct-05 & 0.01 & 0.01 & $\mathrm{NT}^{a)}$ \\
\hline 8FBL04 & France & Loire valley & Bouille Lorets & 23-Jul-08 & 0.07 & $>100$ & NT \\
\hline 8FMU07 & France & Burgundy & Meursault & 9-Sep-08 & 0.06 & $>100$ & NT \\
\hline $8 \mathrm{FSS} 02$ & France & Loire valley & St. Martin de Sanzay & 23-Jul-08 & 0.17 & $>100$ & NT \\
\hline
\end{tabular}

a) NT: Not Tested. 

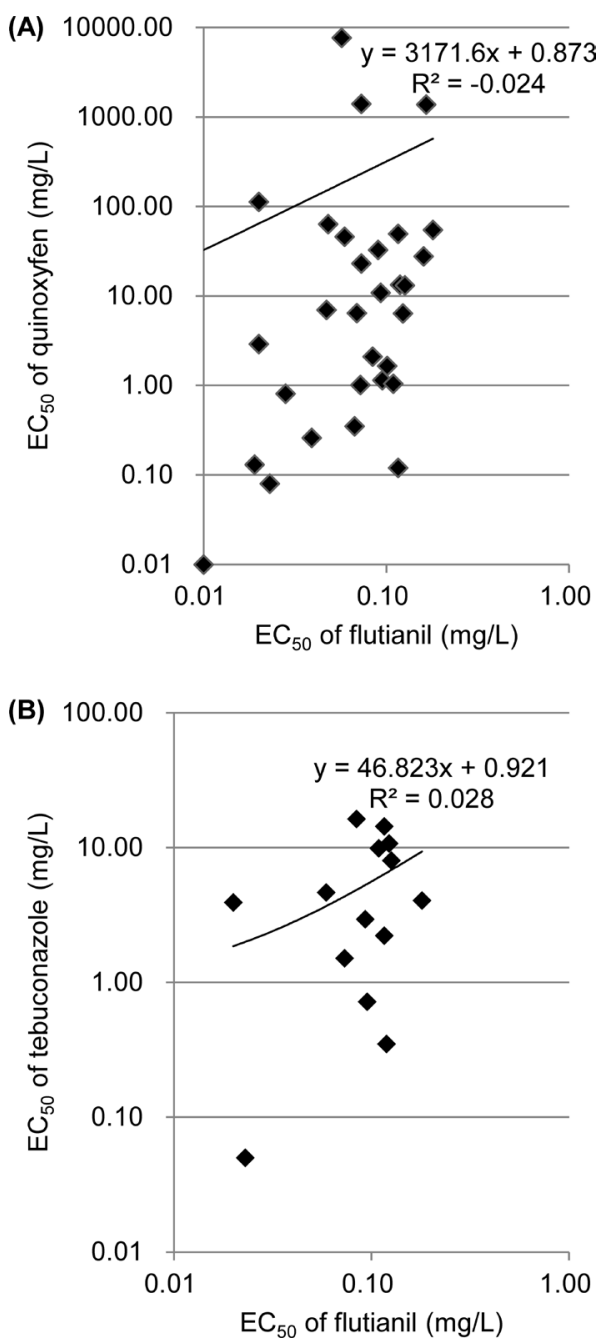

Fig. 2. Cross-sensitivity relationship between (A) flutianil and quinoxyfen, and (B) flutianil and tebuconazole in Erysiphe necator according to $\mathrm{EC}_{50}$ values.

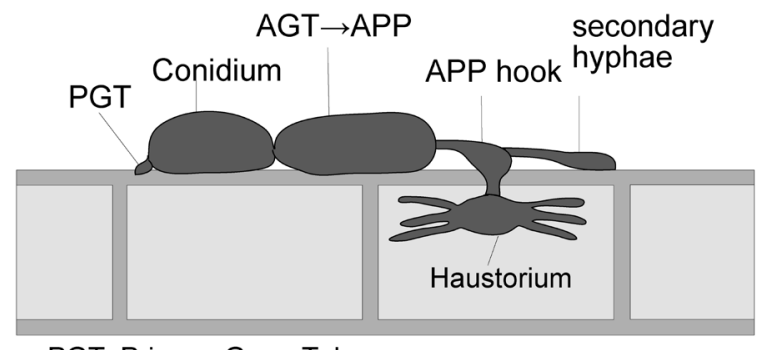

PGT: Primary Germ Tube

AGT: Appressorial Germ Tube

APP: Appressorium

Fig. 3. Schematic diagram of the early infection process of Blumeria graminis f. sp. hordei in barley plant tissues.

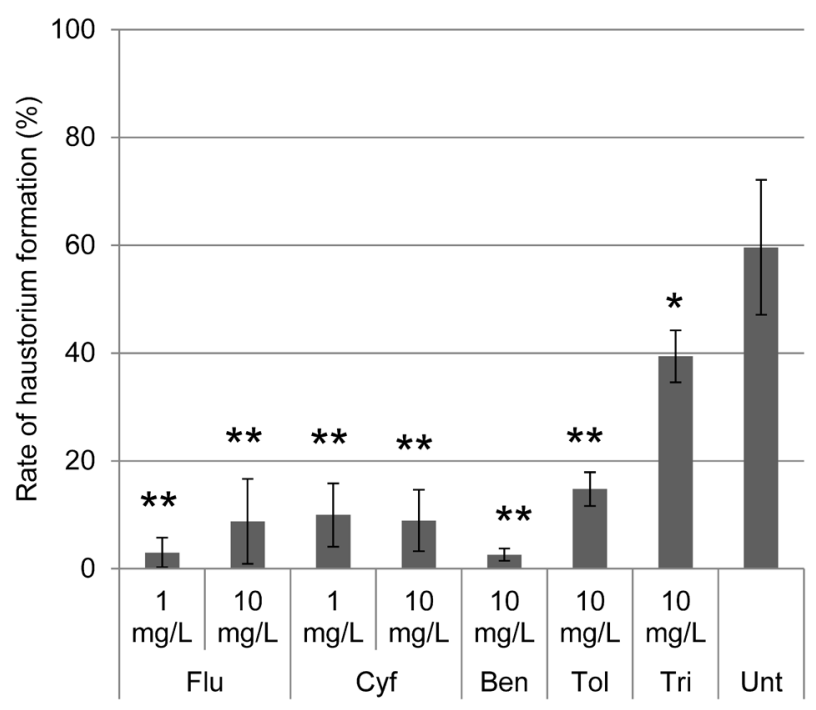

Fig. 4. Effects of flutianil and other existing fungicides on haustorium development in Blumeria graminis f. sp. hordei. The percentage of haustorium development was determined $48 \mathrm{hr}$ after treatment. The tests were repeated 5 times. Statistical analysis was performed using a one-sample Student's $t$-test. ** Indicates a significant $p$ value $<0.01$; Indicates a significant $p$ value $<0.05$. Flu, flutianil; Cyf, cyflufenamid; Ben, benomyl; Tol, tolfenpyrad; Tri, triflumizole; Unt, untreated.

Table 6. Comparison of in vivo inhibitory effect on Blumeria graminis f. sp. hordei (Bgh) between flutianil and existing fungicides at $\left.10 \mathrm{mg} / \mathrm{L}^{\mathrm{a}}\right)$

\begin{tabular}{|c|c|c|c|c|c|c|}
\hline Compound & Conidium bursting & PGT germination & AGT germination & APP formation & APP hook formation & Haustorium formation \\
\hline Flutianil & - & - & - & - & - & ++ \\
\hline Triflumizole & - & - & - & ++ & - & + \\
\hline Azoxystrobin & ++ & ++ & & & & \\
\hline Tolfenpyrad & - & - & + & & & ++ \\
\hline Quinoxyfen & - & ++ & ++ & ++ & ++ & \\
\hline Benomyl & - & - & - & ++ & ++ & ++ \\
\hline Chinomethionat & - & ++ & ++ & ++ & ++ & \\
\hline Cyflufenamid & - & - & - & - & - & ++ \\
\hline Metrafenone & - & - & - & ++ & ++ & \\
\hline
\end{tabular}

a) +-++: Inhibited, -:not inhibited. Blank: Additional microscopic analysis of Bgh was unable to conduct because fungal development was not observed. PGT: Primary Germ Tube. AGT: Appressorial Germ Tube. APP: Appressorium. 


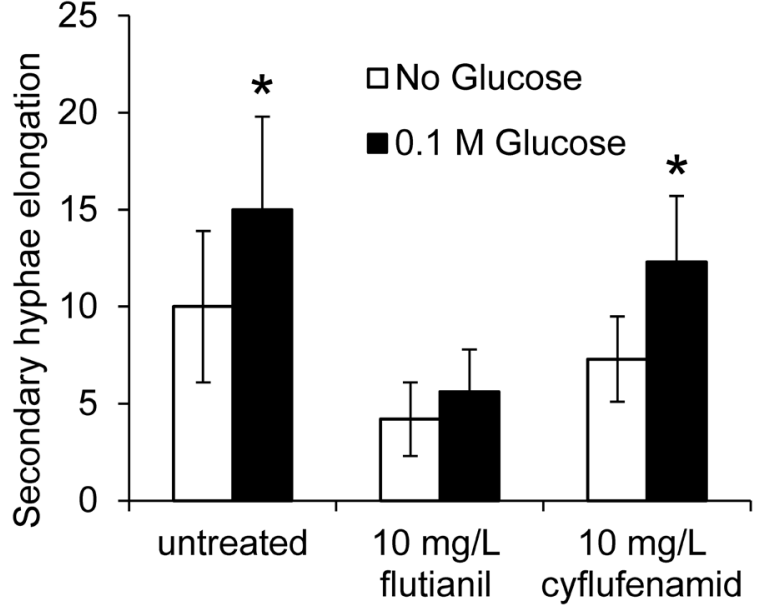

Fig. 5. Effects of flutianil and cyflufenamid on secondary hyphal elongation with the addition of $0.1 \mathrm{M}$ glucose in Blumeria graminis f. sp. hordei. Hyphal elongation is on an eyepiece micrometer scale. The tests were repeated 6 times. Error bars: standard deviation. The lengths of secondary hyphae after glucose addition were compared to those before glucose addition. Statistical analysis was performed using a one-sample Student's $t$-test. $p$ values $<0.05$ were considered to be significant.

torium formation but not conidium bursting, PGT germination, AGT germination, APP formation, and APP hook formationwas compared with those of 8 existing fungicides. As shown in Table 6 , the inhibitory pattern of cyflufenamid was quite similar to that of flutianil since both fungicides inhibited only haustorium formation. Another 7 fungicides, such as triflumizole, azoxystrobin, quinoxyfen, and metrafenone, showed inhibitory patterns that were different from those of flutianil and cyflufenamid. For example, triflumizole inhibited APP formation and haustorium formation. Benomyl inhibited APP and APP hook formation as well as haustorium formation. Metrafenone inhibited both APP and APP hook formations.

Since the inhibitory patterns of flutianil and cyflufenamid on $B g h$ conidial development were similar, they were investigated if there was any difference in secondary hyphal elongation when glucose was added as a nutrient to the Petri dish in which Bgh conidium-inoculated coleoptiles existed. The elongation rates of secondary hyphae for the untreated and cyflufenamid-treated specimens were 1.5 and 1.7 times higher, respectively, when $0.1 \mathrm{M}$ glucose was added than when it was not added, as shown in Figs. 5 and 6. On the contrary, the elongation rate for flutianil-treated specimens was only 1.2 times higher, being significantly lower as compared to cyflufenamid-treated or untreated specimens. This indicates that the glucose absorption by haustoria and subsequent secondary hyphal elongation were significantly inhibited by flutianil but not by cyflufenamid, suggesting that flutianil's mode of action is different from that of cyflufenamid.

\section{Curative activity of flutianil on $\mathrm{P}$. xanthii}

The curative activity of flutianil was investigated by using inoculated cucumber leaves. It is well known that curative activity is observed when fungicides are applied after fungal infection but not before the onset of symptoms (pre-symptoms), while eradicant activity is observed when fungicides are applied after the onset of symptoms (post-symptoms). ${ }^{13)}$ As shown in Table 7, when sprayed onto cucumber leaves 1 day after the inoculation of conidia, flutianil showed $100 \%$ control against P. xanthii. Flutianil's inhibitory activity was maintained for up to 14 days after inoculation, although there was a gradual decrease in activity over the days following flutianil inoculation (50\% inhibition on day 5 to $10 \%$ inhibition on day 14). Microscopic observation indicated abnormal conidiophore formation from 5 to 14 days (post-symptoms) after flutianil treatment, while no additional secondary P. xanthii infection was observed. Thus, flutianil demonstrated curative activity.

Cryo-SEM observation was made to see the effect of flutianil on mycelium and conidiophore formation using flutianil-treated and untreated cucumber leaves 14 days after the inoculation of $P$. xanthii. The untreated leaves were found to be covered with mycelium and numerous conidiophores consisting of a mother cell that produced chains of conidia separated by regularly spaced septa (Fig. 7). On the contrary, in flutianil-treated $(10 \mathrm{mg} / \mathrm{L})$ leaves, conidiophores had formed abnormally as elongated tubes, but the collapse of conidiophores or mycelium was

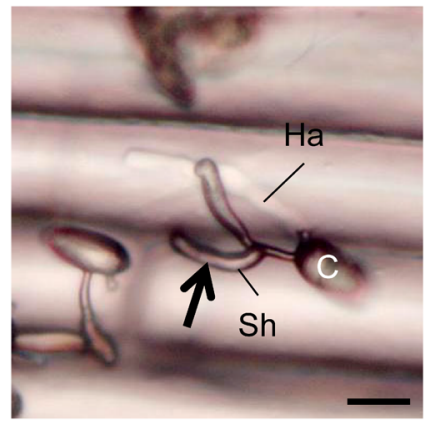

$10 \mathrm{mg} / \mathrm{L}$ flutianil

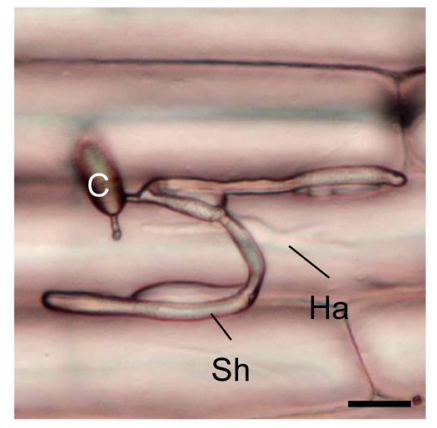

$10 \mathrm{mg} / \mathrm{L}$ cyflufenamid

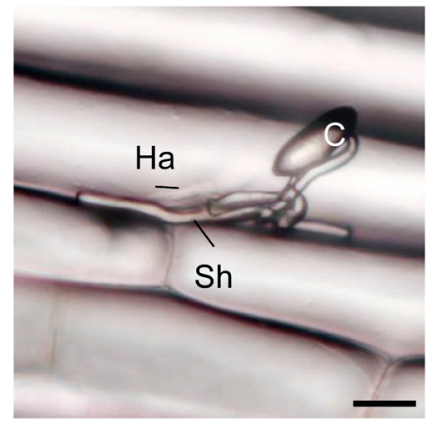

untreated

Fig. 6. Morphological comparisons between flutianil $(10 \mathrm{mg} / \mathrm{L})$, cyflufenamid $(10 \mathrm{mg} / \mathrm{L})$, and untreated control on secondary hyphae during haustorium formation of Blumeria graminis $\mathrm{f}$. sp. hordei. The picture shows the secondary hyphal elongation after the addition of $0.1 \mathrm{M}$ glucose at $24 \mathrm{hr}$. The samples were exposed to $10 \mathrm{mg} / \mathrm{L}$ of flutianil (arrow) or $10 \mathrm{mg} / \mathrm{L}$ of cyflufenamid for $48 \mathrm{hr}$. Sh, secondary hyphae; Ha, haustorium; C, conidium. 
Table 7. Curative activity of flutianil against Podosphaera xanthii

\begin{tabular}{|c|c|c|c|c|c|c|c|}
\hline \multirow{3}{*}{ Compound } & & \multicolumn{6}{|c|}{ Time interval between flutianil application and inoculation } \\
\hline & & \multirow{2}{*}{$\begin{array}{c}\text { Pre-symptoms } \\
1 \mathrm{~d}^{a)}\end{array}$} & \multicolumn{5}{|c|}{ Post-symptoms } \\
\hline & & & $5 \mathrm{~d}$ & $7 \mathrm{~d}$ & $9 \mathrm{~d}$ & $12 \mathrm{~d}$ & $14 \mathrm{~d}$ \\
\hline \multirow[t]{3}{*}{$10 \mathrm{mg} / \mathrm{L}$ of flutianil } & Control value & 100 & 50 & 25 & 30 & 20 & 10 \\
\hline & Sporulation $^{b)}$ & $\mathrm{NF}$ & $\mathrm{ACF}$ & $\mathrm{ACF}$ & ACF & ACF & ACF \\
\hline & Secondary infection ${ }^{c)}$ & - & - & - & - & - & - \\
\hline
\end{tabular}

a) Flutianil was sprayed onto the cucumber leaves $1,5,7,9,12$, and 14 days after inoculation, $(n=3) .{ }^{b}$ NF, not formed; ACF, abnormal conidiophores formed. Observation was made 7 days after flutianil treatment by microscope, $\left.(n=3){ }^{c}\right)$, not infected. $(n=3)$.

not observed.

\section{Discussion}

It is interesting to note that flutianil has excellent antifungal activity against powdery mildew on various crops but no direct inhibitory effects on the growth of many other plant pathogenic fungi. High residual activity and rainfastness which were confirmed by current studies are characteristic features of flutianil. In addition, flutianil showed translaminar activity and curative activity at extremely low concentrations. Overall, these biological properties are likely to contribute to flutianil's excellent efficacy in practical field conditions.

The inhibitory pattern of flutianil on powdery mildew is quite characteristic. Flutianil brought about significant reduction in the haustorium formation of $B g h$ conidia by preventive treatment and inhibited further fungal development up to the secondary hyphal elongation but did not inhibit conidium bursting, PGT and AGT germination, and APP and APP hook formations. By curative treatments, flutianil also inhibited the late infection processes of the pathogen, including the formation of conidiophores and the release of conidia from conidiophores. This inhibitory pattern of flutianil in the infection process is quite different from those of other existing fungicides. For example, triflumizole has been shown to affect the formation of APP hook and haustorium. ${ }^{14)}$ Azoxystrobin has been shown to significantly reduce the spore germination of Cladosporium and Mycosphaer- ella. ${ }^{15)}$ Quinoxyfen is reported to significantly inhibit the formation of APP and APP hooks. ${ }^{16)}$ Metrafenone has been shown to inhibit the germination of conidia and to affect the germination location; subsequently formed APP have frequently presented two or three lobes, which have often been malformed. ${ }^{17)}$ Cyflufenamid it inhibits the formation of haustoria as does flutianil, but it has been shown not to affect the germination of conidia or the formation of APP. ${ }^{18)}$

The inhibitory pattern of flutianil in the life cycle of powdery mildew is thus quite different from that of existing fungicides except for cyflufenamid. Flutianil and cyflufenamid showed the same inhibitory pattern up to the haustorium formation stage in the life cycle of powdery mildew. However, there were differences between the two fungicides in the nutrient absorption by haustoria and subsequent secondary hyphal elongation, which was inhibited by flutianil but not by cyflufenamid. More evidence of the different inhibitory patterns is flutianil's effectiveness against $P$. xanthii and $S$. aphanis var. aphanis, against which cyflufenamid is less effective. It is assumed that flutianil's mode of action is different not only from that of cyflufenamid but also from those of other existing fungicides.

It is interesting to know whether the action of flutianil, an antifungal agent, is fungistatic or fungicidal. In general, fungistatic compounds are able to slow or retard the multiplication of fungi, as represented by fluconazole, which inhibits the growth of fungi. ${ }^{19)}$ In contrast, fungicidal compounds, such as azoxys-

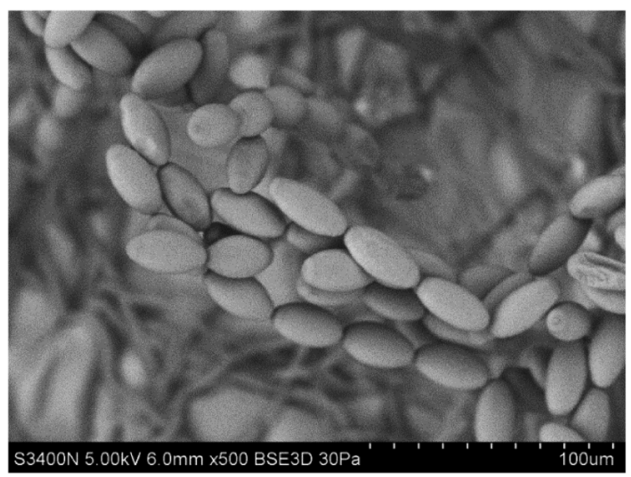

untreated

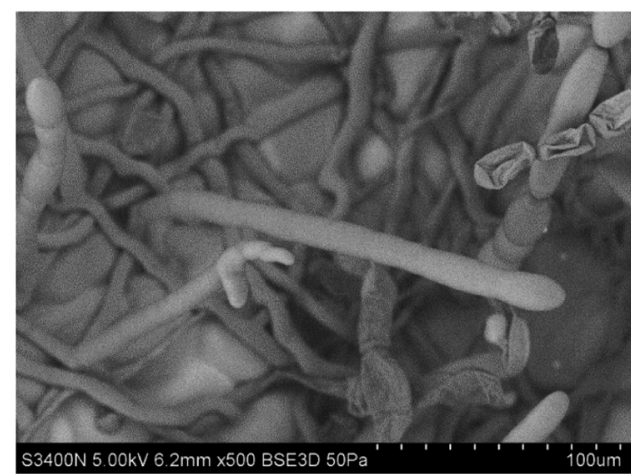

$10 \mathrm{mg} / \mathrm{L}$ flutianil

Fig. 7. Cryo-SEM observation of conidiophores of $P$. xanthii with treatment of $10 \mathrm{mg} / \mathrm{L}$ flutianil. In the untreated control, conidiophores were produced as a chain of conidia separated by regularly spaced septa. In contrast the conidiophores were tubular in flutianil-treated $\mathrm{Bgh}$. 
trobin, kill the fungal pathogens in action. ${ }^{20)}$ Since powdery mildew fungus is an obligate biotroph, it is not possible to directly judge whether flutianil kills the fungus. Current curative treatment studies for flutianil, as well as morphological studies of $B g h$ and $P$. xanthii, have revealed that flutianil caused the formation of abnormal conidiophores, like elongated tubes. However, the collapse of the conidiophores or mycelium was not observed, and the pathogen still seemed alive. Thus, flutianil has fungistatic rather than fungicidal properties. It has been reported that the difference between fungicidal and fungistatic action somehow depends on the concentration of the antifungal agents. ${ }^{21)}$ In the case of flutianil, the optimal concentration to express antifungal effects in pot tests was less than $10 \mathrm{mg} / \mathrm{L}$. Even at $100 \mathrm{mg} / \mathrm{L}$, flutianil did not cause the collapse of the fungal body, although the data are not shown in the text. The action of flutianil still seems to be fungistatic rather than fungicidal on Bgh and P. xanthii. Further studies on the fungistatic properties of flutianil are now in progress.

Current studies indicate that flutianil has curative activity against powdery mildew in addition to preventive activity, since flutianil treatment on cucumber leaves 5-14 days after the inoculation of P. xanthii inhibited the secondary infection of conidiophores and conidial release through morphogenic effects. Flutianil can be used preventively or in a very early stage of disease infection to achieve optimal control. The use of flutianil in this way is especially important to prevent or delay the development of resistance. A curative treatment with flutianil in the post-symptom stage may increase the risk of resistance development due to an increase of the allowed frequency of isolate survival, which would consequently accelerate the speed of resistant isolate selection.

When launching new fungicides, the establishment of baseline sensitivity data for them is very important from the perspective of managing fungicide resistance. Baseline sensitivity data can be used to illustrate shifts in pathogen sensitivity and provide evidence that any control failures might be correlated with the appearance of resistance in the population. ${ }^{22)}$ It is useful that the baseline sensitivity data for E. necator with flutianil was established by determining the control values of flutianil in various areas in Europe by leaf disc assay.

As mentioned, flutianil exhibited excellent control against $P$. xanthii at a very low concentration, and it possibly acts on specific target sites of powdery mildew. Detailed studies on the mode of action of flutianil are in progress.

\section{Acknowledgements}

The authors gratefully acknowledge the work of past and present members of Research and Development Division of OAT Agrio Co., Ltd. We also wish to thank Dr. N. Umetsu, Visiting Professor of Kibi International University for helpful discussion and comments on the manuscript.

\section{References}

1) K. Amano: "Host Range and Geographical Distribution of the Powdery Mildew Fungi," Japan Scientific Societies Press, Tokyo, 1986.

2) S. E. Perfect and J. R. Green: Mol. Plant Pathol. 2, 101-108 (2001).

3) R. P. Oliver and H. G. Hewitt: "Fungicides in Crop Protection," eds. by P. Oliver R.P. and H.G. Hewitt, 2nd Ed. CABI, Wallingford, 2014.

4) D. Raederstorff and M. Rohmer: Eur. J. Biochem. 164, 421-426 (1987).

5) V. L. Garau, A. Angioni, A. A. Del Real, M. Russo and P. Cabras: J. Agric. Food Chem. 50, 1929-1932 (2002).

6) M. Tsuda, H. Itoh and S. Kato: Pest Manag. Sci. 60, 875-880 (2004).

7) I. E. Wheeler, D. W. Hollomon, G. Gustafson, J. C. Mitchell, C. Longhurst, Z. Zhang and S. J. Gurr: Mol. Plant Pathol. 4, 177-186 (2003).

8) K. S. Opalski, S. Tresch, K. H. Kogel, K. Grossmann, H. Köhle and R. Hückelhoven: Pest Manag. Sci. 62, 393-401 (2006).

9) H. Ishii and D. W. Hollomon: "Fungicide Resistance in Plant Pathogens: Principles and a Guide to Practical Management," Springer, Tokyo. 2015.

10) M. Hayashi, Y. Endo, T. Komura, S. Kimura and H. Oka: J. Pestic. Sci. 45, 105-108 (2020).

11) https://www.frac.info/images/default-source/home/poster-logo2. jpg?sfcrsn-7a64499a_2 (Accessed 22 June, 2020)

12) N. Yamaoka: Ann. Phytopathol. Soc. Jpn. 59, 487-491 (1993).

13) T. Craffi and V. Rossi: Phytopathol. Mediterr. 57, 153-169 (2018).

14) A. Nakata, S. Hashimoto, K. Ikura and K. Katsuura: J. Pestic. Sci. 16, 301-313 (1991).

15) J. Bertelsen and R. E. Neergaard: Plant Pathol. 50, 190-205 (2001).

16) I. E. Wheeler, D. W. Hollomon, G. Gustafson, J. C. Mitchell, C. Longhurst, Z. Zhang and S. J. Gurr: Mol. Plant Pathol. 4, 177-186 (2003).

17) K. S. Opalski, S. Tresch, K. Kogel, K. Grossmann, H. Köhle and R. Hückelhoven: Pest Manag. Sci. 62, 393-401 (2006).

18) M. Haramoto, H. Hamamura, S. Sano, F. G. Felsenstein and H. Otani: J. Pestic. Sci. 31, 397-404 (2006).

19) J. S. Lewis and J. R. Graybill: Expert Opin. Pharmaco. 9, 927-935 (2008).

20) D. W. Bartlett, J. M. Clough, J. R. Godwin, A. A. Hall, M. Hamer and B. Parr-Dobrzanski: Pest Manag. Sci. 58, 649-662 (2002).

21) S. J. Haward, J. Livermore, A. Sharp, J. Goodwin, L. Gregson, A. Alastruey-Izquierdo, D. S. Perlin, P. A. Warn and W. W. Hope: Antimicrob. Agents Chemother. 55, 4880-4887 (2010).

22) P. E. Russell: "Sensitivity Baseline in Fungicide Resistance Research and Management," FRAC, Crop Life International, Brussel, pp. 1-60, 2002. 